\title{
Female are More Prone to Halitosis Due to the Changing of the Hormonal Balance-A Cross Sectional Study in Bangladesh
}

\author{
S M Mahmudul Hasan ${ }^{1 *}$, Sumia Afrin ${ }^{2}$ and Nafees Uddin Chowdhury ${ }^{3}$ \\ ${ }^{1}$ Kumudini Women's Medical College, Bangladesh \\ ${ }^{2}$ Saphena Women's Dental College, Bangladesh \\ ${ }^{3}$ Kumudini Women's Medical College, Bangladesh
}

*Corresponding author: S M Mahmudul Hasan, Kumudini Women's Medical College, Bangladesh

To Cite This Article: S M Mahmudul Hasan. Female are More Prone to Halitosis Due to the Changing of the Hormonal Balance-A Cross Sectional Study in Bangladesh. Am J Biomed Sci \& Res. 2019 - 3(2). AJBSR.MS.ID.000643. DOI: 10.34297/AJBSR.2019.03.000643

Received: February 02, 2019 | Published: May 25, 2019

Abstract

Introduction: Halitosis is the highly public health concern and about female are commonly affect this problem. A steroid sex hormone that acts as an important role in maintaining of oral physiology. The menstrual cycle pointed as a constituent that causes halitosis. The prevalence rate of halitosis during menstrual cycle unknown and various sociodemo graphic factors associated to the halitosis.

Objective: The purpose of the survey was to get out the sociodemographic factors that cause halitosis during the menstrual phase.

Methods: This study was cross-sectional survey, covering in Dhaka district of Bangladesh and data collecting period February 2017 to January 2018. The menstruation is 28 days between the days menstrual phase-1-4, follicular phase-7-11 and premenstrual phase-24-27 days. Anxiety score measured by using the Beck Anxiety Inventory (BAI) questionnaire. Factors of halitosis during menstrual cycle risk measured by cross-tabulation and ordinal logistic regression were used to examine the association between sociodemo graphic factors halitosis during menstrual cycle.

Results: Results showed that about $75 \%$ of participant were suffering from severe halitosis. In the adjusted model, high-level anxiety versus low-level anxiety (AOR=0.05,95\% $\mathrm{CI}=0.02,0.23)$ and medium level anxiety $(\mathrm{AOR}=0.09,95 \% \mathrm{CI}=0.02,2.69)$; rural versus urban $(\mathrm{AOR}=3.41,95 \%$ $\mathrm{CI}=1.24,9.34$ ) was significant for malodor during the menstrual phase.

Conclusion: This work confirmed the demographic factors were exacerbated oral halitosis during the menstrual phase.

\section{Introduction}

Halitosis defined as an unpleasant mouth odor due to some intra oral and extra oral causes [1]. It has a significant impact on the person's normal social life. Now it was considering as a public health problem because many people suffering from halitosis $[2,3]$. About $31 \%$ of American adults suffering from chronic or recurrent halitosis and almost 45\% Indian dental student reported halitosis [4]. There are many extra-oral and intraoral factors causes halitosis such as periodontitis, gingival bleeding, tongue coating, oral ulcer, dental caries, respiratory disturbance such as sinusitis, nasal discharge, carcinoma of lung, infection and various systemic diseases like diabetes mellitus, uremia and digestion diseases $[5,6]$. Oral mucosa is more sensitive to changes of hormone and it is more sensitive for the changes of women sex steroid [7]. This change of oral normal condition causes dryness and discomfort feeling of the female.

Endocrine system affects the maintenances the normal oral environment. Previous some studied showed that sex hormone that is estrogen and progesterone have an influence on periodontal tissues. Some studies have assessed the association between oral malodor during the menstrual phase and they said that oral malodor is caused by the Volatile Sulphur Compounds (VSC). This VSC produced by the action of anaerobic gram-negative bacteria [8]. Some study said that halitosis during menstruation cycle caused by hormonal changes [2]; some said due to dryness of mouth during menstruation cycle [7] some are said about some other factors [9]. That means the causes of halitosis during menstruation phase is still controversial. The aim of the study was to find out the factors that causes halitosis during menstrual phase.

\section{Methods}

\section{Participant}

This study employed cross-sectional survey, covering both rural and urban areas in Dhaka district of Bangladesh. Data was collected in the period from February 2017 to January 2018. All participant 
must be healthy and completely free of systemic diseases. All participant completed an information including demographic data, history of smoking and habits. Patient must had at least 20 teeth, no dental caries, calculus, no defective restoration and no impacted or partially impacted 3rd molar teeth or no tongue coating. The participant also used to dentifrice without antimicrobial agents. That means, only those participants in perfect oral and systemic health were included for this study. Women were selected those had normal regular menstrual cycles lasting from 25-35 days; were not pregnant, had not taken any oral contraceptive in the last 6 months. The menstrual cycle time were in the ranges 24-34 days where variability not more than 5 days. Every participant was examined once during the menstrual phase, once during the follicular phase and once during the premenstrual phase. According to normal physiology, the menstruation is 28 days that's why examination took place between the 1-4 days for menstrual phase, days 24 to 27 days for premenstrual phase and 7-11 days for follicular phase. The examination ranges for every phase was adjusted according to the participant's average cycle length, taken for 6 months evaluation by the calendar method. The premenstrual phase was detected by the women's report on the onset of her menstrual phase. Sample were selecting purposively.

\section{Procedures}

Every diagnosis done designated research room and evaluated at the same time every weekday to minimize the influence the biological rhythms. Data were collected and examined when the participant were not suffering any stressful events or had no academic examination. Participant anxiety level were examined by Beck anxiety inventory and halitosis measured by organoleptic method.

\section{Beck Anxiety Inventory (BAI)}

Patient advised to complete the Beck Anxiety Inventory (BAI) questioner. BAI contained 21 questions that helped to measure the degree of severity level of anxiety, according to BAI it rated as four- point scale- "not at all" to "severely". Then the scores interpreted-0-21 indicated low level of anxiety, 22-35 indicated moderate anxiety and more than 36 indicated severe level of anxiety. The instrument has valid internal consistency $(\alpha=0.92)$ and high-retest reliability $(\mathrm{r}=0.75)$ [10].

\section{Organoleptic test}

Organoleptic method is the gold standard method for measuring and assessing bad smell [11]. This method is a simple commonly used measurement method. At first a plastic tube inserted patient's mouth, preventing the dilatation of the mouth air with the room air. Then the patient inhaled slowly, and the examiner judges the odor at the other end of the tube. A separator with a hole for tube used for separating between examiner and participant. Nasal-breath examined by one nostril while another nostril closed by finger [12]. The effectiveness of odor measured by using Rosenberg scale from 0 to 5 which is as follows: $0=$ no odor, $1=$ barely noticeable odor, $2=$ slight but clearly noticeable odor, $3=$ moderate odor, $4=$ strong offensive odor, $5=$ extremely foul odor [13]. The participant with Rosenberg scale 0 and 1 considered as no odor, 2 considered as mild odor, 3 considered as moderate odor and 4 and 5 considered as severe odor. For getting good results the participant followed the following rules a, avoided to using any type of oral rinse or mouth freshener for one week before the examination day $b$, abstain to eating spicy food that contained onion or garlic 24 hours before the experiment $\mathrm{c}$, avoid to eating and drinking for at least 8 hours before the experiment, although they were allowed to drink water up to 3 hours before the examination d, avoided smoking, taking antibiotics before examination $[12,14,15]$. In addition, the dentist avoided drinking coffee, tea, juice, smoking and using scanted cosmetic before the organoleptic measurement [12]. Spoon test was evaluating at the distance approximately five $\mathrm{cm}$ form the examiner nose [15] and the dental floss odor test determined the presence of interdental plaque odor [15]. Organoleptic measurement conducted by three expert dentists. The kappa index for evaluated the examiner.

\section{Ethical considerations}

This study protocol was reviewed and approved by the Hasan Eye and Dental Hospital, Bangladesh. Prior to the survey, participants were informed about the study, invite to participate, and informed of their right to decline. All clinical waste materials those used for this study was disposed of safely.

\section{Statistical analysis}

Sociodemographic factors that were related to halitosis analyzed by descriptive statistics. Sociodemo graphic differences in halitosis during menstrual cycle risk were assessed by crosstabulation. Because the outcome measure was ordinal, both unadjusted and adjusted ordered logistic regression were used to analyze the association between sociodemo graphic factors and predicted risk of halitosis during menstrual cycle. All covariates were entered simultaneously into the ordinal logistic regression models. All analysis was done by using SPSS (Version 22.0, Chicago, IL, USA) software, considering the level of significance in $5 \%$.

Results

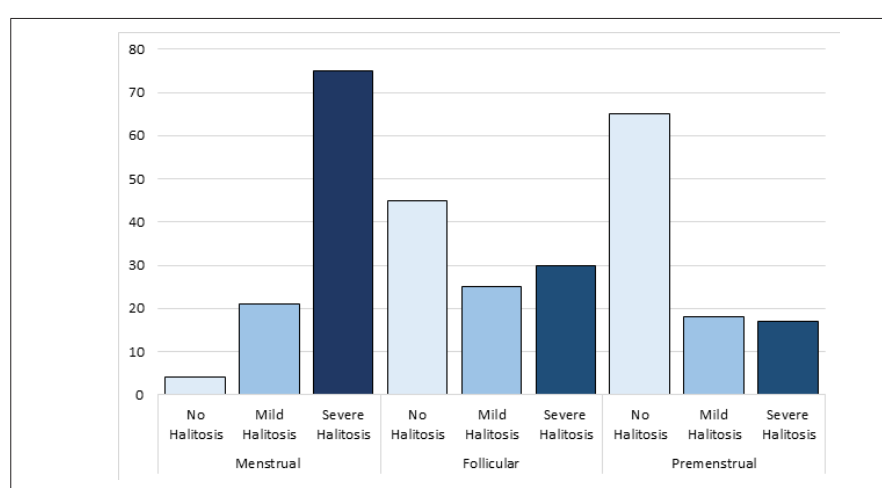
cycle.

Figure 1: Level of Halitosis in different phase of Menstruation

Finally, the data of 100 subjects were analyzed and $75 \%$ of participant were suffering from severe halitosis and $21 \%$ were suffering from mild halitosis. Although, it was about $30 \%$ \& $25 \%$ for follicular phase and $17 \%$ \& $18 \%$ for premenstrual phase according to severe and mild halitosis (Figure 1). 
Table 1 presents sample descriptive and evaluates variation in menstrual cycle phases as a function of age, residential area, marital status, gum bleeding and level of anxiety. Here about $36 \%$ respondent are 21-25 years old, 60\% lived in urban area and $47 \%$ are medium level of anxious at the time of survey. There was about
$40 \%$ of elderly (31-35) patient showed severe halitosis during her menstrual phase. About $58.7 \%$ of participant showed severe level of halitosis, those showed bleeding during examination and $47 \%$ were suffering from medium level of anxiety during their menstrual phase.

\begin{tabular}{|c|c|c|c|c|c|c|c|c|c|c|}
\hline \multicolumn{11}{|c|}{ Phase } \\
\hline $\begin{array}{l}\text { Character- } \\
\text { istics }\end{array}$ & $\begin{array}{c}\text { Number } \\
(\%)\end{array}$ & \multicolumn{3}{|c|}{ Premenstrual (\%) } & \multicolumn{2}{|c|}{ Follicular (\%) } & \multicolumn{4}{|c|}{ Menstrual (\%) } \\
\hline $\begin{array}{c}\text { Age of re- } \\
\text { spondent, } \\
\text { yrs. }\end{array}$ & & $\begin{array}{l}\text { No Hali- } \\
\text { tosis }\end{array}$ & $\begin{array}{l}\text { Mild Hali- } \\
\text { tosis }\end{array}$ & $\begin{array}{c}\text { Severe } \\
\text { Halitosis }\end{array}$ & $\begin{array}{c}\text { No Hali- } \\
\text { tosis }\end{array}$ & $\begin{array}{l}\text { Mild Hali- } \\
\text { tosis }\end{array}$ & $\begin{array}{c}\text { Severe } \\
\text { Halitosis }\end{array}$ & $\begin{array}{l}\text { No Hali- } \\
\text { tosis }\end{array}$ & $\begin{array}{l}\text { Mild Hali- } \\
\text { tosis }\end{array}$ & $\begin{array}{c}\text { Severe } \\
\text { Halitosis }\end{array}$ \\
\hline $21-25$ & $36(36)$ & 43.1 & 33.3 & 11.8 & 48.9 & 32 & 20 & 100 & 38.1 & 32 \\
\hline $26-30$ & $30(30)$ & 35.3 & 0 & 41.2 & 28.9 & 36 & 26.7 & 0 & 42.9 & 28 \\
\hline $31-35$ & $34(34)$ & 21.5 & 66.7 & 47.1 & 22.2 & 32 & 53.3 & 0 & 19 & 40 \\
\hline p-value & & \multicolumn{3}{|c|}{0.001} & \multicolumn{3}{|c|}{0.042} & \multicolumn{3}{|c|}{0.028} \\
\hline \multicolumn{11}{|l|}{ Residence } \\
\hline Rural & $40(40)$ & 21.5 & 77.8 & 29.4 & 22.2 & 24 & 80 & 50 & 90.5 & 52 \\
\hline Urban & $60(60)$ & 78.5 & 22.2 & 70.6 & 77.8 & 76 & 20 & 50 & 9.5 & 48 \\
\hline p-value & & \multicolumn{3}{|c|}{0} & \multicolumn{3}{|c|}{0} & \multicolumn{3}{|c|}{0.006} \\
\hline \multicolumn{11}{|l|}{$\begin{array}{l}\text { Marital } \\
\text { status }\end{array}$} \\
\hline Single & $43(43)$ & 60 & 11.1 & 11.8 & 60 & 32 & 26.7 & 0 & 42.9 & 64 \\
\hline Married & $57(57)$ & 40 & 88.9 & 88.2 & 40 & 68 & 73.3 & 100 & 57.1 & 36 \\
\hline p-value & & \multicolumn{3}{|c|}{$<0.001$} & \multicolumn{3}{|c|}{0.007} & \multicolumn{3}{|c|}{0.014} \\
\hline \multicolumn{11}{|l|}{$\begin{array}{l}\text { Bleeding } \\
\text { of the gum }\end{array}$} \\
\hline No & $53(53)$ & 78.5 & 11.1 & 0 & 91.1 & 40 & 6.7 & 100 & 85.7 & 41.3 \\
\hline Yes & $47(47)$ & 21.5 & 88.9 & 100 & 8.9 & 60 & 93.3 & 0 & 14.3 & 58.7 \\
\hline p-value & & \multicolumn{3}{|c|}{$<0.001$} & \multicolumn{3}{|c|}{$<0.001$} & \multicolumn{3}{|c|}{$<0.001$} \\
\hline \multicolumn{11}{|l|}{ Anxiety } \\
\hline Low & $33(33)$ & 36.9 & 22.2 & 29.4 & 35.6 & 44 & 20 & 0 & 42.9 & 32 \\
\hline Medium & $47(47)$ & 50.8 & 33.3 & 47.1 & 60 & 32 & 40 & 100 & 57.1 & 41.3 \\
\hline High & $20(20)$ & 12.3 & 44.4 & 23.5 & 4.4 & 24 & 40 & 0 & 0 & 26.7 \\
\hline p-value & & \multicolumn{3}{|c|}{0.054} & \multicolumn{3}{|c|}{0.002} & \multicolumn{3}{|c|}{0.017} \\
\hline $\begin{array}{l}\text { Preva- } \\
\text { lence }\end{array}$ & & 65 & 18 & 17 & 45 & 25 & 30 & 4 & 21 & 75 \\
\hline
\end{tabular}

Table 2: Odds ratio for association between ages, anxiety level, bleeding form gum, sociodemographic characteristics against Risk of oral malodor in menstrual phase.

\begin{tabular}{|c|c|c|c|c|}
\hline Characteristics & Unadjusted 0R (95\% CI) & p-value & Adjusted 0R (95\% CI) & \\
\hline Age of respondent (yrs.) & & $<0.001$ & $0.47(0.15,1.46)$ \\
\hline $21-25$ & $0.12(0.05,0.31)$ & 0.001 & $0.31(10.05,0.92)$ \\
\hline $26-30$ & $0.18(0.07,0.49)$ & & 1 \\
\hline $31-35$ & 1 & $<0.001$ & $0.05(0.02,0.23)$ \\
\hline Anxiety Level & $0.05(0.02,0.17)$ & $<0.001$ & $0.09(0.02,2.69)$ \\
\hline Low & $0.05(0.02,0.16)$ & & 1 \\
\hline Medium & 1 & & 0.001 \\
\hline High & & & \\
\hline Bleeding of the gum & $0.03(0.01,0.09)$ & $<0.001$ & $9.84(0.03,2.31)$ \\
\hline
\end{tabular}




\begin{tabular}{|c|c|c|c|c|}
\hline Residence & & & & \\
\hline Urban & $6.46(2.79,14.91)$ & $<0.001$ & $3.41(1.24,9.34)$ & 1 \\
\hline Rural & 1 & & & 0.017 \\
\hline Marital status & & & $0.34(0.12,0.93)$ & \\
\hline Married & $0.11(0.05,0.27)$ & $<0.001$ & 1 & 0.036 \\
\hline Single & 1 & & \\
\hline
\end{tabular}

In the unadjusted ordinal logistic regression models, being aged 21-25 and 26-30 versus 31-35 years, having bleeding absent versus bleeding present, level of anxiety low and medium versus high, urban versus rural residence and married versus single participant were significantly suffering malodor during their menstrual phase. In the adjusted model, high level anxiety versus low level anxiety $(\mathrm{AOR}=0.05,95 \% \mathrm{CI}=0.02,0.23)$ and medium level anxiety (AOR=0.09,95\% CI=0.02,2.69); rural versus urban (AOR=3.41,95\% CI=1.24,9.34); bleeding of gum present versus absent (AOR=9.84,95\% CI=0.03,2.31), Single versus Married (AOR=0.34,95\% CI=0.12,0.93) were significant for malodor during the menstrual phase. In addition, 26-30 years participant were associated with oral malodor (Table 2).

\section{Discussion}

Halitosis has an important negative role in social status. Few studies are reporting the prevalence of halitosis in general population also in women during their menstrual cycle. This study result showed oral halitosis increase in menstrual phase and decrease in premenstrual phase. That means changes of level of sex hormone has an effect their oral condition. Although some covariates like anxiety, bleeding of gum and age of the participant. The relationship between stress and changing of hormonal level was known by the ancient civilization. However, changing of hormonal level has a relation on oral halitosis is not widely studied. One of the problems of the study is the effect of stress in humans is to stimulate adequately a stressful situation. Our findings showed that there has a significant level of relationship between oral halitosis and anxiety. In the unadjusted analysis, there was significant level of relationship present on the level of anxiety and halitosis level. In addition, it was more in middle age group. Changing of hormonal level in female are occurring every month actively [16]. Some study showed significant and observable gingival inflammatory changes occurs [17-20]. This inflammatory change causes bleeding from the gum. In addition, bleeding on the gum is the cardinal sign of gingivitis. This Gingivitis causes oral halitosis.

All women who suffered from the premenstrual syndrome has higher halitosis. Previous studies showed similar results [14,21]. Pain and anxiety is more in the special period of the women life. The limitation of the study, unable to measure the volatile Sulphur compound due to unavailable of measuring machine. However, another variable were measure correctly. In addition, it should be remembered that study was carried out in nonsmoker participant.

\section{Conclusion}

In conclusion, this study showed that some demographic factor with some external factors exacerbates oral halitosis during menstrual phase. It seems that different sex hormone causes halitosis in different phases. However, some surrounding factors influencing that and causes severe problem. This subject needs more research for discovering the possible causes.

\section{Funding}

The author(s) received no financial support for the research, authorship and/or publication of this article.

\section{Conflict of Interest}

The author(s) declared no potential conflicts of interest with respect to the research, authorship, and/or publication of this article.

\section{References}

1. Rayman S, Almas K (2008) Halitosis among racially diverse populations: an update. International journal of dental hygiene 6(1): 2-7.

2. Tonzetich J, Preti G, Huggins GR (1978) Changes in concentration of volatile sulphur compounds of mouth air during the menstrual cycle. Journal of International Medical Research 6(3): 245-254.

3. Rosenberg M (1990) Bad breath, diagnosis and treatment. University of Toronto dental journal 3: 7-11.

4. Setia S, Pannu P, Gambhir RS, Galhotra V, Ahluwalia P, et al. (2014) Correlation of oral hygiene practices, smoking and oral health conditions with self-perceived halitosis amongst undergraduate dental students. Journal of natural science, biology, and medicine 5(1): 67-72.

5. Van den Broek AM, Feenstra L, de Baat C (2007) A review of the current literature on aetiology and measurement methods of halitosis. Journal of dentistry 35(8): 627-635.

6. Cortelli JR, Barbosa MDS, Westphal MA (2008) Halitosis a review of associated factors and therapeutic approach. Brazilian oral research 22 Suppl 1: 44-54.

7. Mirzaii Dizgah I, Agha Hosseini F (2011) Stimulated and unstimulated saliva progesterone in menopausal women with oral dryness feeling. Clin Oral Investig 15(6): 859-862.

8. De EB, De MU, Loesche W (1994) Relationship between volatile sulfur compounds, BANA-hydrolyzing bacteria and gingival health in patients with and without complaints of oral malodor. J Clin Dent 4(4): 114-119.

9. Kakoei S, Barkhori F, Mirzazadeh A, Mohammadi M, Gholamhoseinian A (2015) Influence of menstrual cycle and salivary ß-estradiol on volatile sulfur compound. Journal of Oral Health \& Oral Epidemiology 1(1): 4145.

10. Beck AT, Steer RA (1990) Manual for the Beck anxiety inventory. San Antonio, TX: Psychological Corporation.

11. Nalçacı R, Sönmez IS (2008) Evaluation of oral malodor in children. Oral Surgery, Oral Medicine, Oral Pathology, Oral Radiology, and Endodontology 106(3): 384-388.

12. Yaegaki K, Coil JM (2000) Examination, classification, and treatment of halitosis; clinical perspectives. Journal-canadian dental association 66(5): 257-261. 
13. Rosenberg M, Gelernter I, Barki M, Bar Ness R (1992) Day-long reduction of oral malodor by a two-phase oil: water mouthrinse as compared to chlorhexidine and placebo rinses. Journal of periodontology 63(1): 39-43.

14. Calil CM, Marcondes FK (2006) Influence of anxiety on the production of oral volatile sulfur compounds. Life sciences 79(7): 660-664.

15. Rosenberg M (1996) Clinical assessment of bad breath: current concepts. Journal of the American Dental Association 1939 127(4): 475-482.

16. Mealey BL, Moritz AJ (2003) Hormonal influences: effects of diabetes mellitus and endogenous female sex steroid hormones on the periodontium. Periodontology 2000 32: 59-81.

17. Gusberti F, Syed S, Bacon G, Grossman N, Loesche W (1983) Puberty gingivitis in insulin-dependent diabetic children: I. Cross-sectional observations. Journal of periodontology 54(12): 714-720.
18. Lindhe J, Attström R (1967) Gingival exudation during the menstrual cycle. Journal of periodontal research 2(3): 194-198.

19. Mariotti A (1999) Dental plaque-induced gingival diseases. Annals of periodontology 4(1): 7-17.

20. Sutcliffe P (1972) A longitudinal study of gingivitis and puberty. Journal of Periodontal Research 7(1): 52-58.

21. Queiroz CS, Hayacibara MF, Tabchoury CPM, Marcondes FK, Cury JA (2002) Relationship between stressful situations, salivary flow rate and oral volatile sulfur-containing compounds. European journal of oral sciences 110(5): 337-340. 